\title{
Blastocyst formation by pig embryos resulting from in-vitro fertilization of oocytes matured in vitro
}

\author{
M. Yoshida, Y. Ishizaki and H. Kawagishi \\ Faculty of Agriculture, Shizuoka University, Shizuoka 422, Japan
}

\begin{abstract}
Summary. Follicular oocytes collected from prepubertal gilts at a local slaughter house were matured $(36 \mathrm{~h})$, fertilized and developed in vitro. Of 785 embryos, $190(24 \%)$ embryos cleaved to the 2-4-cell stages with blastomeres of regular size by $33 \mathrm{~h}$ after insemination. These cleaved embryos were surgically transferred into the oviducts of 4 synchronized recipient gilts and recovered from the uterine horns 4 or 7 days later: 13 morulae, 2 blastocysts and 1 expanded blastocyst were recovered after 4 days and 3 hatched blastocysts were recovered 7 days after transfer. Re-culture in vitro sustained further development of morulae recovered 4 days after transfer: 11 of 13 morulae had developed to the blastocyst/hatched blastocyst stages. Overall, 17 of $190(9 \%)$ embryos developed to the blastocyst stage. The results indicate that pig oocytes can be matured and fertilized in vitro, and subsequently develop to the blastocyst stage.
\end{abstract}

Keywords: maturation; in vitro; fertilization; oocyte; blastocyst; pig

\section{Introduction}

The ovaries of slaughtered farm animals could provide a sufficient supply of embryos for embryo transfer and manipulation of embryos if ovarian oocytes could be matured, fertilized and cultured in vitro.

The viability to term of pig embryos resulting from in-vitro fertilization of oocytes matured in wivo has been reported by Cheng (1985), Yoshida $(1987,1989)$ and Nagai et al. (1988). However, invitro fertilization of pig oocytes matured in vitro has only resulted in the formation of early embryonic stages (Iritani et al., 1978; Nagai et al., 1984) and full viability has not been tested.

The objective of this study was to examine, by transfer to synchronized gilts, the viability of pig embryos resulting from in-vitro fertilization of oocytes matured in vitro.

\section{Materials and Methods}

The methods for preparation of spermatozoa, in-vitro fertilization and transfer of embryos were based on those described by Yoshida $(1987,1989)$.

Collection of oocytes. Ovaries were collected from prepubertal gilts at a local slaughter house and transported to the laboratory in $0.9 \%(\mathrm{w} / \mathrm{v}) \mathrm{NaCl}$ containing $100 \mathrm{mg}$ kanamycin sulphate/l (Meiji Seika, Tokyo, Japan) at about $35^{\circ} \mathrm{C}$. Within $2 \mathrm{~h}$ of slaughter, the oocyte-cumulus complexes were recovered by aspiration, using a 5-ml disposable syringe, from the follicles (2-5 mm in diameter) and washed twice with Medium PBI (Whittingham, 1971) and with the maturation medium, respectively. Only oocytes possessing a compact cumulus mass and evenly granulated ooplasm were selected for the experiments.

In-vitro maturation. Oocytes (10-15) were transferred to a droplet of maturation medium $(0.2 \mathrm{ml})$ in a polystyrene dish ( $35 \mathrm{~mm}$ : Becton Dickinson Labware, Oxnard, CA, USA) and cultured for $36 \mathrm{~h}$. After culture, oocytes with an expanded cumulus mass were selected and subjected to insemination.

Preparation of spermatozoa. The sperm-rich fractions were obtained from 2 Large White boars using the glovedhand method. Semen samples were washed three times with $0.9 \%(\mathrm{w} / \mathrm{v}) \mathrm{NaCl}$ containing $100 \mathrm{mg}$ BSA/l (Sigma Chemical Co., St Louis, MO, USA) and $100 \mathrm{mg}$ kanamycin sulphate/l. Washed spermatozoa were subsequently 
diluted to $2 \times 10^{8}$ cells $/ \mathrm{ml}$ in the sperm preincubation medium and incubated for $4 \mathrm{~h}$ at $37^{\circ} \mathrm{C}$ in a tightly capped test-tube.

In-vitro fertilization and embryo culture. After incubation, oocytes (40-45) were transferred to fertilization medium $(2.0 \mathrm{ml})$ covered with paraffin oil (Nakarai Chemical Co., Kyoto, Japan). The spermatozoa were diluted to $2 \times 10^{7}$ cells $/ \mathrm{ml}$ and introduced in the fertilization medium to make a final concentration of $5 \times 10^{5}$ cells $/ \mathrm{ml}$. After $6-7 \mathrm{~h}$ incubation, the oocytes were removed from the surrounding cumulus mass and spermatozoa by agitation using a narrowbore glass pipette and washed twice with embryo culture medium $(2.0 \mathrm{ml})$. Then, $5-10$ oocytes were transferred to a droplet of embryo culture medium $(0 \cdot 1 \mathrm{ml})$. To examine the rates of maturation and fertilization, some embryos were randomly removed $18 \mathrm{~h}$ after insemination and fixed with acetic alcohol (methanol and acetic acid, 3:1, v/v) and stained with $1 \%$ aceto-orcein. The stages of these embryos were determined by means of Nomarski differential interference microscopy (Olympus Co.. Tokyo, Japan): embryos with a polar body were regarded as matured and embryos having the enlarged sperm head or male pronucleus with sperm tail were regarded as fertilized.

The remaining oocytes were cultured for further development. At $33 \mathrm{~h}$ after insemination, 2-4-cell embryos with blastomeres of regular size were picked up; and any remaining cumulus cells and spermatozoa on the zona pellucida were removed as described above. The embryos were washed twice with the medium $(2.0 \mathrm{ml})$ and transferred to droplets of fresh medium $(0.4 \mathrm{ml})$ and incubated until transfer. The assessment for cleavage was performed using an inverted microscope (Olympus).

Transfer of embryos. Four mature gilts (crossbred Landrace $\times$ Large White), aged $9 \cdots 10$ months, were used as recipients. The recipients received a single intramuscular injection of 1000 i.u. PMSG (Teikoku Zoki Co., Tokyo, Japan) on Day 16 of the oestrous cycle followed by 500 i.u. hCG (Sankyo Co., Tokyo, Japan) $72 \mathrm{~h}$ later. Transfer of embryos was performed under general anaesthesia through mid-ventral laparotomy 2 days after hCG injection. Embryos were transferred to the oviducts of recipient gilts $36-37 \mathrm{~h}$ after insemination: 2 -cell embryos developed by $33 \mathrm{~h}$ of culture were transferred to the oviduct on one side and 3-4-cell embryos developed by $33 \mathrm{~h}$ of culture were transferred to the contralateral oviduct. The recipients were slaughtered 4 days $(\mathrm{N}=3)$ or 7 days $(\mathrm{N}=1)$ later. The uteri were removed and immediately flushed with $200 \mathrm{ml}$ Medium PB 1 . The embryos were examined for development under an inverted microscope. The embryos recovered 4 days after transfer were cultured in vitro in embryo culture medium $(0.1 \mathrm{ml})$ for a further $24 \mathrm{~h}$ and fixed and stained for microscopic examination after culture. The embryos recovered 7 days after transfer were immediately fixed and stained using the methods described above.

Culture media and culture conditions. The basic medium (Medium B) consisted of TCM-199 with Earle's salts (Nissui Pharmaceutical Co., Tokyo, Japan) supplemented with $100 \mathrm{mg}$ sodium pyruvate/l (Sigma), $550 \mathrm{mg}$ glucose/l (Wako Pure Chemical Co., Oosaka, Japan), $900 \mathrm{mg}$ calcium lactate/1 (Nakarai), $100 \mathrm{mg}$ dibekacin sulphate/l (Meiji) and $10 \%(\mathrm{v} / \mathrm{v})$ fetal calf serum (FCS; GIBCO, Grand Island, NY, USA). The $\mathrm{pH}$ of Medium B after equilibration with $5 \% \mathrm{CO}_{2}$ in air was 7.4. Medium $\mathrm{B}$ adjusted to $\mathrm{pH} 7.8$ was used for sperm preincubation. The adjustment of $\mathrm{pH}$ of this medium was performed by adding $7.5 \%(\mathrm{w} / \mathrm{v}) \mathrm{NaHCO}_{3}($ Wako $)$ solution. Medium B enriched with $10 \mathrm{i} . \mathrm{u} . \mathrm{PMSG} / \mathrm{ml}$, $10 \mathrm{i} . \mathrm{u} . \mathrm{hCG} / \mathrm{ml}, 1 \mu \mathrm{g}$ oestradiol- $17 \beta / \mathrm{ml}$ (Sigma) and a partly purified fraction of pig follicular fluid $(10 \% ; \mathrm{v} / \mathrm{v})$ was used for maturation. The fractionation of follicular fluid was performed as follows; fluid from antral follicles ( $2-5 \mathrm{~mm}$ in diameter) was centrifuged once at room temperature at $1500 \mathrm{~g}$ for $30 \mathrm{~min}$. And then the supernatant was ultrafiltrated with a UK-200 membrane filter (Advantec Toyo Co., Tokyo, Japan) at $4^{\circ} \mathrm{C}$ to obtain the fraction of $M_{\mathrm{r}}<200000$. The filtrate was further concentrated by ultrafiltration using a PM-10 filter (Amicon, Lexington, KY, USA) and then directly applied to a column of Toyopearl 55S (Toyosotatsu Industry Co., Tokyo, Japan: $1000<M_{1}<700000$ ) equilibrated with Dulbecco's phosphate-buffered saline. Fractions were monitored for protein by absorbance at $280 \mathrm{~nm}$. The first fraction obtained by gel filtration was applied to a column of DEAE-Toyopearl (Toyosotatsu) after equilibration with starting buffer $(10 \mathrm{mM}$-phosphate buffer, $\mathrm{pH} 6.1)$ and eluted by applying a linear salt gradient $(0-0.5 \mathrm{M}-\mathrm{NaCl})$. The third fraction obtained by ion-exchange chromatography was concentrated by ultrafiltration using a PM- 10 membrane filter and stored at $-20^{\circ} \mathrm{C}$. This material was diluted to the original volume obtained by ultrafiltration with UK-200 in distilled water and referred to as the partly purfified fraction of pig follicular fluid. Medium B enriched with $2 \mathrm{~mm}$-caffeine (Wako) was used for fertilization medium. The embryo culture medium consisted of TCM-199 with Earle's salts supplemented with $40 \mathrm{mg}$ sodium pyruvate $/ 1,3.7 \mathrm{ml}$ sodium lactate $/ 1$ (60\% syrup; Sigma), $100 \mathrm{mg}$ dibekacin sulphate $/ 1$ and $10 \%$ (v/v) FCS.

In-vitro culture of oocytes, in-vitro fertilization and embryo culture were performed at $38.5 \mathrm{C}$ in an atmosphere of $5 \% \mathrm{CO}_{2}$ in air. The handling of oocytes and embryos under the microscope was performed at $38^{\circ} \mathrm{C}$ on a heated stage (Kitazato Supply Co., Tokyo, Japan).

\section{Results}

Of 966 oocytes cultured in vitro, $838(87 \%)$ had an expanded cumulus mass (Fig. 1) and these oocytes were used for insemination. At $18 \mathrm{~h}$ after insemination (Table I), the maturation rate and fertilization rate of embryos were high. However, the polyspermic fertilization rate of fertilized embryos was also high. Although female pronuclei were developed in all the fertilized embryos, male pronuclei were observed in $60 \%(27 / 45)$ of them. The polygynic fertilization, defined as 
fertilized embryos having two or more female pronuclei, was a small proportion. The normal fertilization rate assessed by the number of embryos having two polar bodies and one set of male and female pronuclei (Fig. 2) was low.

Table 1. Results at $18 \mathrm{~h}$ after insemination of invitro fertilization of pig oocytes matured in vitro

\begin{tabular}{lcc}
\hline & \multicolumn{2}{c}{ No. $(\%)$ of oocytes } \\
\hline Nuclear maturation & $48 / 53$ & $(90 \cdot 6)$ \\
Fertilization & $45 / 53$ & $(84 \cdot 9)$ \\
Normal & $7 / 45^{*}$ & $(15 \cdot 6)$ \\
Polyspermic & $28 / 45^{*}$ & $(62 \cdot 6)$ \\
Polygynic & $5 / 45^{*}+(11 \cdot 1)$ \\
\hline
\end{tabular}

*Oocytes fertilized.

IIncludes three polyspermic oocytes

Of 785 embryos, $391(49 \%)$ had cleaved $36 \mathrm{~h}$ after insemination, and $190(24 \%)$ had cleaved to 2- (Fig. 3) to 4-cell stages with blastomeres of regular size by $33 \mathrm{~h}$ after insemination. The other embryos had cleaved irregularly or showed signs of fragmentation.

After transfer of 2-4-cell embryos to recipient gilts, the rates of recovery were higher for 2-cell than for 3-4-cell embryos both at 4 and 7 days after transfer (Table 2). At 4 days after transfer, 16 embryos had developed to at least the morula stage (13 morulae, 2 blastocysts (Fig. 4 ) and 1 expanded blastocyst) and these were from the uteri of 3 recipients. At 7 days after transfer, 3 hatched blastocysts were recovered from the uteri of 1 recipient.

As shown in Table 3, re-culture in vitro for $24 \mathrm{~h}$ sustained further development of morulae and blastocysts recovered 4 days after transfer; 11 of 13 morulae had developed to the blastocyst or hatched blastocyst stages and 3 blastocysts had developed to the expanded/hatched blastocyst stages (Figs $5 \& 6$ ). The number of nuclei per blastocyst recovered at 4 days and re-cultured ranged from 22 to 150 (mean: 56.4$)$; most $(50 \%)$ had $30-50$ nuclei, $29 \%$ had $>60$ nuclei and 2 hatched blastocysts had 150 nuclei. Three hatched blastocysts recovered 7 days after transfer had more than 200 nuclei. However, the rate of blastocyst formation and the number of nuclei per blastocyst were higher for 2-cell than for 3-4-cell embryos. Overall, 17 of 190 embryos (9\%) formed a blastocyst after transfer and re-culture in vitro.

\section{Discussion}

The results of this study show that pig oocytes can be matured and fertilized in vitro, and subsequently develop to the blastocyst stage. In the pig, some normal embryos have been obtained from gilts after transfer of oocytes collected from gilts as early as $24-28 \mathrm{~h}$ after hCG injection (Leman \& Dziuk, 1971). Nevertheless, Polge (1977) reported that pig oocytes matured in vitro and fertilized in vivo did not develop to the blastocyst stage. On the other hand, Dziuk (1960) reported that ova recovered from unmated gilts at 8 and 10 days after oestrus were fragmented and resembled shrunken blastocysts. Hunter \& Nichol (1988) found that boar spermatozoa surgically inseminated into the isthmus $36-40 \mathrm{~h}$ before ovulation had the ability to fertilize pig oocytes. Therefore, there are risks that blastocyst formation may have been due to fragmentation of native ova or in-vivo fertilization of native ova by spermatozoa transplanted with the in-vitro fertilized embryos.

However, it is considered that blastocysts obtained in the present study were originated from embryos being transferred, and not from those being ovulated from recipient gilts (native ova). The reasons for this are as follows. (1) Blastocysts obtained in the present study were not shrunken and some were developed to the expanded to hatched blastocyst stages. Moreover, these blastocysts had 

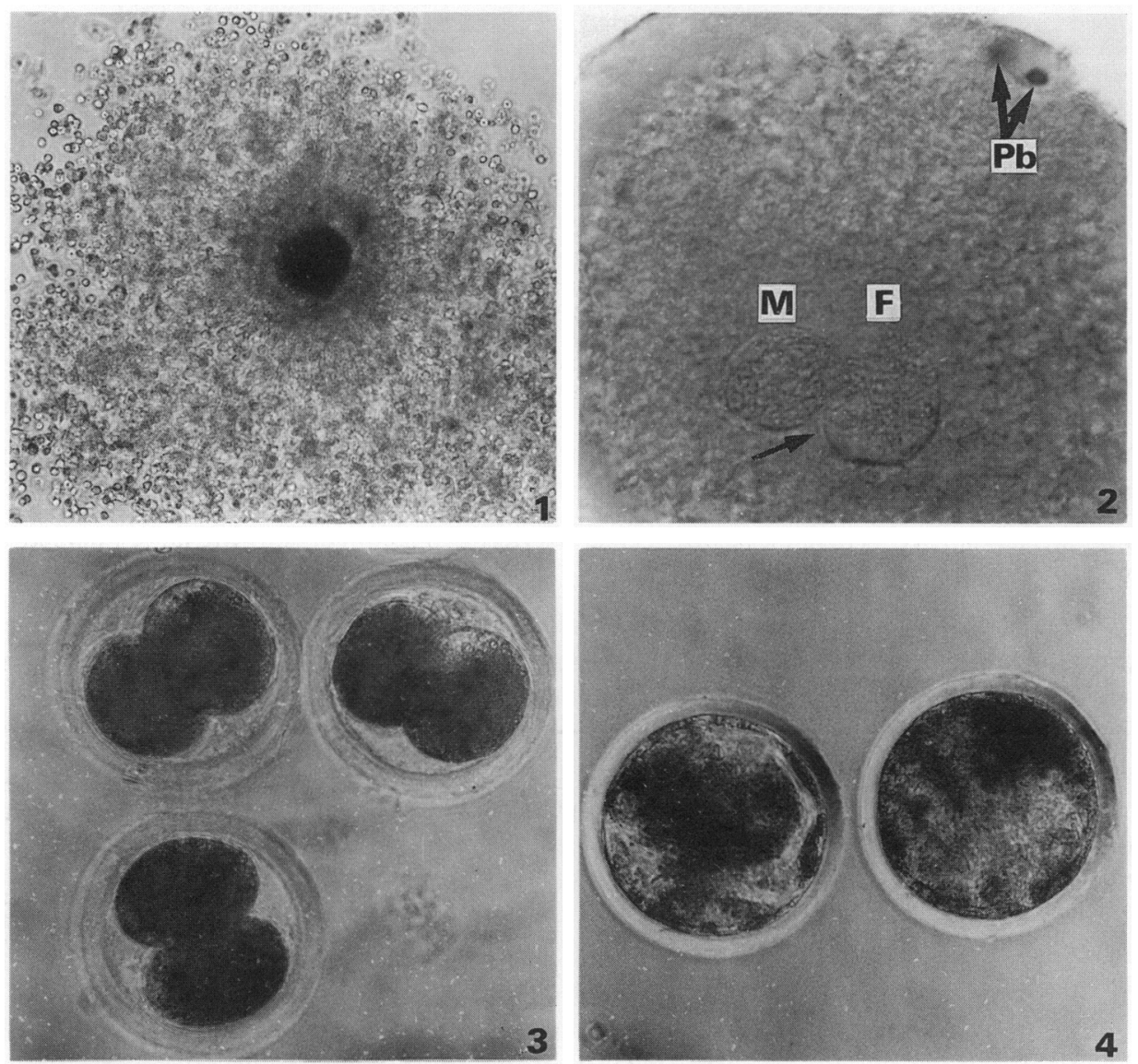

Fig. 1. An oocyte with expanded cumulus mass, recovered at 36 h of culture. $\times 75$.

Fig. 2. An oocyte $18 \mathrm{~h}$ after insemination, showing a male pronucleus (M) with sperm tail (arrow), a female pronucleus $(\mathrm{F})$ and two polar bodies $(\mathrm{Pb}$. $) \times 450$.

Fig. 3. Two-cell pig embryos resulting from in-vitro fertilization of oocytes matured in vitro: $33 \mathrm{~h}$ after insemination. $\times 180$.

Fig. 4. Two blastocysts recovered 4 days after transfer to a recipient gilt. $\times 182$.

Table 2. Results of recovery of embryos from recipient gilts

\begin{tabular}{|c|c|c|c|c|c|c|c|c|c|}
\hline $\begin{array}{l}\text { Days } \\
\text { after } \\
\text { transfer }\end{array}$ & $\begin{array}{c}\text { No. of } \\
\text { CL* }^{*}\end{array}$ & $\begin{array}{c}\text { Stage of } \\
\text { embryos } \\
\text { transferred }\end{array}$ & $\begin{array}{c}\text { No. of } \\
\text { embryos } \\
\text { transferred }\end{array}$ & $\begin{array}{l}\text { No. }(\%) \text { of } \\
\text { embryos } \\
\text { recoveredt+ }\end{array}$ & $\begin{array}{l}1- \\
\text { cell }\end{array}$ & $\begin{array}{l}2-8- \\
\text { cell }\end{array}$ & ntal & ages & $D G$ \\
\hline 4 & $\begin{array}{l}19 \\
12\end{array}$ & $\begin{array}{ll}2 \text {-cell } \\
3 & 4 \text {-cell }\end{array}$ & $\begin{array}{l}86 \\
52\end{array}$ & $\begin{array}{l}83(79 \cdot 1) \\
28(43 \cdot 8)\end{array}$ & $\begin{array}{r}15 \\
3\end{array}$ & $\begin{array}{l}49 \\
20\end{array}$ & $\begin{array}{r}10 \\
3\end{array}$ & $\frac{2}{1}$ & $\begin{array}{l}7 \\
1\end{array}$ \\
\hline 7 & $\begin{array}{l}15 \\
10\end{array}$ & $\begin{array}{r}2 \text { 2-cell } \\
3 \quad 4-c e l l\end{array}$ & $\begin{array}{l}33 \\
19\end{array}$ & $\begin{array}{r}14(29 \cdot 2) \\
3(10 \cdot 3)\end{array}$ & $\begin{array}{l}0 \\
0\end{array}$ & $\begin{array}{l}0 \\
0\end{array}$ & $\begin{array}{l}0 \\
0\end{array}$ & $\begin{array}{l}3 \\
0\end{array}$ & $\begin{array}{r}11 \\
3\end{array}$ \\
\hline
\end{tabular}

\footnotetext{
*In recipients.
}

+ At $33 \mathrm{~h}$ after insemination.

+In relation to the no. of embryos transferred and the no. of $C L$.

$\$ \mathrm{M}=$ morula; $\mathrm{BL}=$ blastocyst $\mathrm{DG}=$ degenerate. 

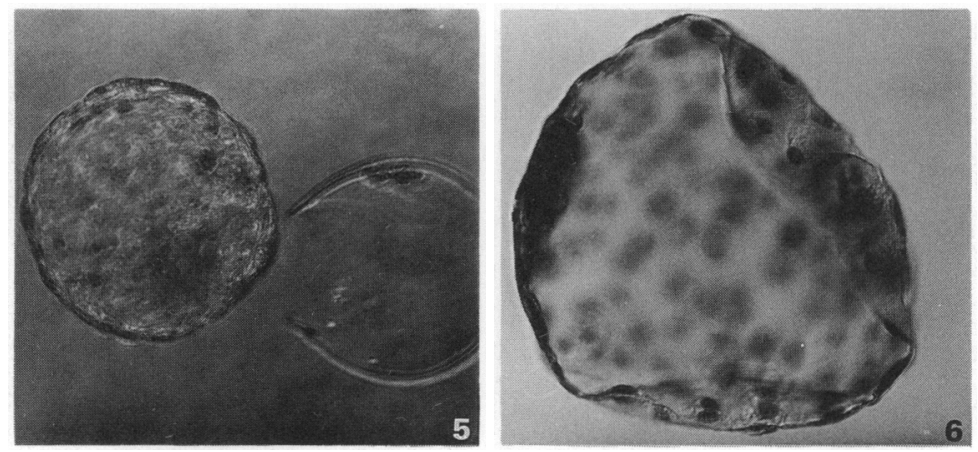

Fig. 5. One hatched blastocyst re-cultured for $24 \mathrm{~h}$, which was at the blastocyst stage at recovery 4 days after transfer. $\times 123$.

Fig. 6. The hatched blastocyst in Fig. 5 after fixation and staining, showing large numbers of nuclei. $\times 363$.

Table 3. Summary of blastocyst formation by pig embryos resulting from in-vitro fertilization of oocytes matured in vitro

\begin{tabular}{|c|c|c|c|c|c|c|}
\hline \multirow{2}{*}{$\begin{array}{l}\text { Days } \\
\text { after } \\
\text { transfer }\end{array}$} & \multirow{2}{*}{$\begin{array}{c}\text { Stage of } \\
\text { embryos } \\
\text { transferred* }\end{array}$} & \multirow{2}{*}{$\begin{array}{c}\text { No. of } \\
\text { embryos } \\
\text { transferred }\end{array}$} & \multicolumn{3}{|c|}{ No. of blastocysts } & \multirow{2}{*}{$\begin{array}{l}\text { Mean no. of } \\
\text { nuclei/blastocyst } \\
\text { (range) }\end{array}$} \\
\hline & & & $\begin{array}{l}\text { Total } \\
(\%)\end{array}$ & $\begin{array}{c}\text { At } \\
\text { recovery }\end{array}$ & $\begin{array}{c}\text { After } \\
\text { re-culture }{ }^{\ddagger}\end{array}$ & \\
\hline 4 & $\begin{array}{r}2 \text {-cell } \\
3-4 \text {-cell }\end{array}$ & $\begin{array}{l}86 \\
52\end{array}$ & $\begin{array}{r}10(11 \cdot 6) \\
4(7 \cdot 7)\end{array}$ & $\begin{array}{l}2 \\
1\end{array}$ & $\begin{array}{l}8 \\
3\end{array}$ & $\begin{array}{l}65 \cdot 8(22-150) \\
31 \cdot 5(28-50)\end{array}$ \\
\hline 7 & $\begin{array}{r}2 \text {-cell } \\
3 \text {-4-cell }\end{array}$ & $\begin{array}{l}33 \\
19\end{array}$ & $\begin{array}{ll}3 & (9 \cdot 1) \\
0 & (0)\end{array}$ & $\begin{array}{l}3 \\
0\end{array}$ & - & $\begin{array}{l}>200 \\
-\end{array}$ \\
\hline Total & 2-4-cell & 190 & $17 \quad(8 \cdot 9)$ & 6 & $1 \mathrm{l}$ & - \\
\hline
\end{tabular}

*At $33 \mathrm{~h}$ after insemination.

+For 24 h after recovery.

more than 30 nuclei and there are no reports that pig ova collected from unmated females can be developed to these stages. Therefore, it is not considered that the blastocyst formation derived from the fragmentation of native ova. (2) Since spermatozoa that surrounded the embryos were carefully removed and the embryos were washed several times before transfer, only small numbers of nonmotile spermatozoa, which appeared to be tightly bound with the zona pellucida of embryos, were observed (Fig. 3), and no spermatozoa were observed in the suspension of transfer medium at transfer. On the other hand, it is reported that spermatozoa capacitated in vitro lose their ability to bind and penetrate the zona pellucida with prolonged incubation in the golden hamster (Barros et al., 1973, 1984), guinea-pig (Fleming \& Yanagimachi, 1982) and human (Singer et al., 1985). For example, human spermatozoa became infertile $24 \mathrm{~h}$ after incubation in vitro (Singer et al., 1985). These reports indicate that the loss of the ability to cross the zona pellucida was correlated with a loss of motility or some morphological changes in the acrosome membrane. In a preliminary experiment, scanning electron microscopy revealed that the acrosome membrane of most $(99 \%)$ boar spermatozoa capacitated in vitro had already changed on the surface of the pig zona pellucida by $6 \mathrm{~h}$ after insemination. Furthermore, boar spermatozoa cultured for more than $18 \mathrm{~h}$ in vitro under the same conditions as in this study completely lost their ability to penetrate the zona pellucida of pig oocytes (unpublished observation). Therefore, we consider that the likelihood of in-vivo fertilization of native ova by zona spermatozoa of transferred embryos is small. 
The methodology for in-vitro maturation and fertilization in the present study resulted in high levels of cumulus expansion, nuclear maturation and fertilization and a low level of polygyny. One of the reasons for this is the addition of partly purified fraction of pig follicular fluid to the oocyte maturation medium; when such a fraction was added to the medium, the rates of cumulus expansion $(93 \%)$ and nuclear maturation $(89 \%)$ of pig oocytes were significantly higher, and the rate of polygynic fertilization $(5 \%)$ was significantly lower than the rates of those $(61 \%, 69 \%$ and $30 \%$, respectively) in the medium without adding this fraction (unpublished data). However, the frequency of polyspermy and the asynchrony of development of male and female pronuclei were high and therefore the rate of normal fertilization was low. Moreover, in-vitro development of pig embryos from oocytes matured and fertilized in vitro was inferior to that of oocytes matured in vivo and fertilized in vitro (Yoshida, 1987, 1989), and in-vivo development of pig embryos from oocytes matured and fertilized in vitro was remarkably inferior to that of oocytes matured and fertilized in vivo (Pursel et al., 1985; Wall et al., 1985). This is probably due to the low level of normal fertilization of pig oocytes matured in vitro in the present study. Since it has been reported that the existence of excessive numbers of capacitated spermatozoa (Hunter \& Leglise, 1971; Hunter, 1973) at the site of fertilization in vivo increased the chance of polyspermic fertilization in the pig, it is not clear whether the high level of polyspermy observed in this study suggests incompleteness of oocyte maturation in vitro. Hanada (1985) reported that the frequency of asynchronous development of male and female pronuclei in bovine oocytes matured and fertilized in vitro varied according to the methods for in-vitro capacitation of spermatozoa. One of the reasons for the high level of asynchrony observed in this study may therefore be the incompleteness of capacitation of spermatozoa in vitro. Another reason may be the various amounts of a cytoplasmic substance responsible for male pronucleus formation in oocytes, as suggested by Xu \& Greve (1988).

Both the rates of recovery of in-vitro fertilized embryos from recipient gilts and the rates of blastocyst formation of them were higher for 2-cell than for 3-4-cell embryos, which seems to be in contrast to what one would expect. It is not certain why both rates were higher for 2-cell embryos but could be due to (1) an abnormal cleavage pattern or (2) the culture system. Kola et al. (1987) provided evidence that tripronuclear human oocytes cleaved directly to 3-cells at first cleavage division. Therefore, most or some of the 3-4-cell embryos obtained in the present study might have been derived from a similar abnormal cleavage pattern. Herrmann \& Holtz (1985) found that the recovery rate and developmental rate of early pig embryos fertilized in vivo and transferred to ligated rabbit oviducts were higher for 2-cell than for 3 4-cell embryos. This indicates that 3-4-cell embryos are more sensitive to in-vitro conditions of manipulation and culture than 2-cell embryos. Additionally, early pig embryos encounter the 4-cell block when they are cultured in vitro (Pope \& Day, 1977; Menino \& Wright, 1982; Polge, 1982; Davis, 1985). The culture system in the present study may therefore not have been suitable for embryos beyond the 3-cell stage. Since the detrimental effects of lactate and pyruvate (Davis \& Day, 1978; Davis, 1985) on pig embryos and the beneficial effects of reduced oxygen atmosphere (Wright, 1977) and co-culture with uterine fibroblasts (Kuzan \& Wright, 1982) on pig embryos have been reported, it will be necessary to examine these factors to improve the viability of pig embryos in vitro.

Embryos forming blastocysts in the present study appeared to cleave and form a blastocyst at a rate similar to that in vivo (Hunter, 1974; Davis, 1985). Since blastocyst formation is believed to be a valid indication of normal maturation, fertilization and development (Moor \& Trounson, 1977; Trounson et al., 1977), the findings in this study provide evidence that pig oocytes can be matured and fertilized in vitro under appropriate conditions. However, blastocoele formation does not necessarily indicate the ability to develop further: some embryos with abnormal karyotypes can form blastocysts and a blastocoele represents function of the trophoblast, not of the inner cell mass cells.

Although pig embryos derived from in-vitro fertilization of oocytes matured in vitro are capable of developing to the blastocyst stage, more studies are required to increase the rate of development and subsequently to achieve normal pregnancy. 
We thank Dr K. Bamba and Dr Y. Kojima for valuable advice; Mr M. Ishibashi and $\mathrm{Mr}$ M. Miyamura for technical assistance; $\mathrm{Mr} \mathrm{Y}$. Kuwahara for supplying the boar semen; $\mathrm{Mr}$ Y. Wakamatsu and Mr Y. Nakamura for care of the animals; and staff, of the Meat Inspection Center, City of Shizuoka, for supplying the pig ovaries. This work was supported by a grant from the Ito Memorial Foundation.

\section{References}

Barros, C., Fujimoto, M. \& Yanagimachi, R. (1973) Failure of zona penetration of hamster spermatozoa after prolonged incubation in a blood serum fraction. $J$. Reprod. Fert. 35, 89-95.

Barros, C., Jedlicki, A., Bize, I. \& Aguirre, E. (1984) Relationship between the length of sperm preincubation and zona penetration in the golden hamster: a scanning electron microscopy study. Gamete Res. 9, $31-43$.

Cheng, W.T.K. (1985) In vitro fertilization of farm animal oocytes. Ph.D. thesis. Council for National Academic Awards.

Davis, D.L. (1985) Culture and storage of pig embryos. J. Reprod. Fert., Suppl. 33, 115-124.

Davis, D.L. \& Day, B.N. (1978) Cleavage and blastocyst formation by pig embryos in vitro. J. Anim. Sci. 46, $1043-1053$.

Dziuk, P. (1960) Frequency of spontaneous fragmentation of ova in unbred gilts. Proc. Soc. exp. Biol. Med. 103, 91-92.

Fleming, A.D. \& Yanagimachi, R. (1982) Fertile life of acrosome-reacted guinea pig spermatozoa. J. exp. Zool. 220, 109-115.

Hanada, A. (1985) In vitro fertilization in cattle-With particular reference to sperm capacitation by ionophore A23187. Jpn. J. Anim. Reprod. 31, 56-61.

Herrmann, H.H. \& Holtz, W. (1985) Storage of pig embryos in the ligated rabbit oviduct and its effect on the viability after re-transfer to synchronized gilts. Anim. Reprod. Sci. 8, 159-170.

Hunter, R.H.F. (1973) Polyspermic fertilization in pigs after tubal deposition of excessive numbers of spermatozoa. J. exp. Zool. 183, 57-64.

Hunter, R.H.F. (1974) Chronological and cytological details of fertilization and early embryonic development in the domestic pig, Sus scrofa. Anat. Rec. 178, $169-186$.

Hunter, R.H.F. \& Leglise, P.C. (1971) Polyspermic fertilization following tubal surgery in pigs, with particular reference to the role of the isthmus. $J$. Reprod. Fert. 24, 233-245.

Hunter, R.H.F. \& Nichol, R. (1988) Capacitation potential of the fallopian tube: a study involving surgical insemination and the subsequent incidence of polyspermy. Gamete Res. 21, 255-266.

Iritani, A., Niwa, K. \& Imai, H. (1978) Sperm penetration of pig oocytes matured in vitro. J. Reprod. Fert. 54, 379-383.

Kola, I., Trounson, A., Dawson, G. \& Rogers, P. (1987) Tripronuclear human oocytes: altered cleavage patterns and subsequent karyotypic analysis of embryos. Biol. Reprod. 37, 395-401.

Kuzan, F.B. \& Wright, R.W., Jr (1982) Blastocyst expan- sion, hatching, and attachment of porcine embryos cocultured with bovine fibroblasts in vitro. Anim. Reprod. Sci. 5, 57-63.

Leman, A.D. \& Dziuk, P.J. (1971) Fertilization and development of pig follicular oocytes. J. Reprod. Fert. 26, 387-389.

Menino, A.R. \& Wright, R.W., Jr (1982) Development of one-cell porcine embryos in two culture systems. $J$. Anim. Sci. 54, 583-587.

Moor, R.M. \& Trounson, A.O. (1977) Hormonal and follicular factors affecting maturation of sheep oocytes in vitro and their subsequent developmental capacity. J. Reprod. Fert. 49, $101-109$.

Nagai, T., Niwa, K. \& Iritani, A. (1984) Effect of sperm concentration during preincubation in a defined medium on fertilization in vitro of pig follicular oocytes. J. Reprod. Fert. 70, 271-275.

Nagai, T., Takahashi, T., Masuda, H., Shioyo, Y., Kuwayama, M., Fukushima, M., Iwasaki, S. \& Hanada, A. (1988) In-vitro fertilization of pig oocytes by frozen boar spermatozoa. J. Reprod. Fert. 84, 585-591.

Polge, C. (1977) In vitro fertilization and use of follicular oocytes. In Embryo Transfer in Farm Animals (Monograph No. 16), 43 pp. Ed. K. J. Betteridge. Agriculture Canada.

Polge, C. (1982) Embryo transplantation and preservation. In Control of Pig Reproduction, pp. 277-291. Eds D. J. A. Cole \& G. R. Foxcroft. Butterworths, London.

Pope, C.E. \& Day, B.N. (1977) Transfer of preimplantation of pig embryos following in vitro culture for 24 or 48 hours. J. Anim. Sci. 44, 1036-1040.

Pursel, V.G., Wall, R.J., Hammer, R.E. \& Brinster, R.L. (1985) Cleavage of pig embryos after labeling with fluorescent dyes. Theriogenology 24, 693-700.

Singer, S.L., Lambert, H., Overstreet, J.W., Hanson, F.W. \& Yanagimachi, R. (1985) The kinetics of human sperm binding to the human zona pellucida and zona-free hamster oocyte in vitro. Gamete Res. 12, 29-39.

Trounson, A.O., Willadsen, S.M. \& Rowson, L.E.A. (1977) Fertilization and development capability of bovine follicular oocytes matured in vitro and in vivo and transferred to the oviducts of rabbits and cows. J. Reprod. Fert. 51, 321-327.

Wall, R.J., Pursel, V.G., Hammer, R.E. \& Brinster, R.L. (1985) Development of porcine ova that were centrifuged to permit visualization of pronuclei and nuclei. Biol. Reprod. 32, 645-651.

Whittingham, D.G. (1971) Survival of mouse embryos after freezing and thawing. Nature, Lond. 233, $125-126$. 
Wright, R.W., Jr (1977) Successful culture in vitro of swine embryos to the blastocyst stage. J. Anim. Sci. 44, 854-858.

Xu, K.P. \& Greve, T. (1988) A detailed analysis of early events during in-vitro fertilization of bovine follicular oocytes. J. Reprod. Fert. 82, 127-134.

Yoshida, M. (1987) In vitro fertilization of pig oocytes matured in vivo. Jpn. J. vet. Sci. 49, 711-718.
Yoshida, M. (1989) Improved viability of two-cell stage pig embryos resulting from in vitro fertilization of oocytes matured in vivo. Jpn. J. Anim. Reprod. 35, $34-37$.

Received 16 December 1988 